\title{
Summer Pruning in Low-Chill Peaches Grown in Florida ${ }^{1}$
}

\author{
Ali Sarkhosh, Dustin Huff, Trequan McGee, and Juanita Popenoe ${ }^{2}$
}

After the harvest season in any peach orchard, large or small, while daily picking may have ceased, the focus quickly shifts to how to manage the trees to support the subsequent year's crop. The strong apical dominance of peach trees will cause them to continuously put energy into upward growth, which ultimately shades out and hinders the development of fruiting wood in the lower portion of the canopy. Low-chill peach trees growing under Florida conditions can become vigorous and large. They have a short period of winter rest and a long growing season after the harvesting period, extending up to 200 days. Water sprouts also develop rapidly in the summer, causing denser vegetation and restricting airflow. Especially in subtropical peach-growing regions, summer pruning is a management strategy that can be applied to help restructure the canopy, direct the tree's resources into fruit production, and improve the efficiency of fieldwork. Without summer pruning, peach orchards in subtropical regions will continue to grow vigorously and, if left unmanaged, will reach a point at which ladders will be required to harvest and maintain the trees (Figure 1). Summer pruning can be a means of reducing overall tree size, redistributing fruiting wood for easier harvesting, reducing disease pressure, and increasing fruit quality.

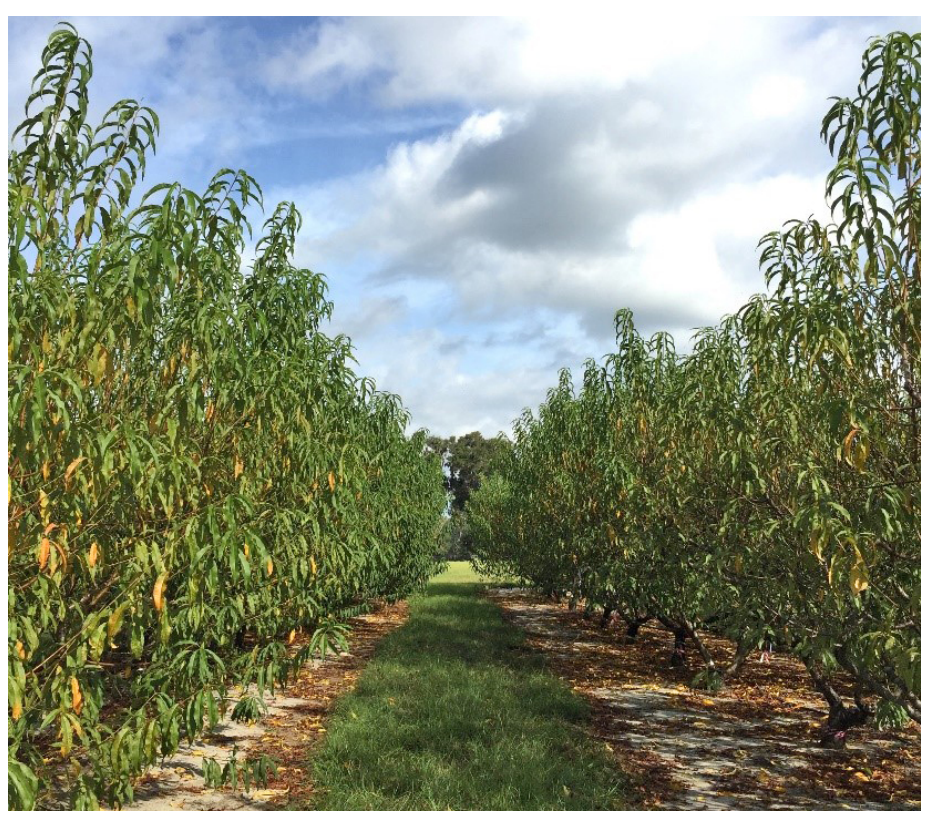

Figure 1. 'UFSun' peach cultivar growth after the harvesting period in June.

Credits: A. Sarkhosh, UF/IFAS

\section{Benefits of Summer Pruning}

Dwarf varieties or dwarfing rootstocks for tree size control are unavailable for commercial-scale peach production. Summer pruning can help achieve control of the size and shape of a peach tree when done at the proper time. When actively growing shoots are pruned back in summer, the ability of trees to replenish their resources is diminished

1. This document is HS1377, one of a series of the Horticultural Sciences Department, UF/IFAS Extension. Original publication date October 2020. Visit the EDIS website at https://edis.ifas.ufl.edu for the currently supported version of this publication.

2. Ali Sarkhosh, assistant professor and Extension specialist; Dustin Huff, biological scientist; Trequan McGee, graduate student; Horticultural Sciences Department; and Juanita Popenoe, multi-county commercial fruit production agent IV, UF/IFAS Extension Lake County; UF/IFAS Extension, Gainesville, FL 32611.

The Institute of Food and Agricultural Sciences (IFAS) is an Equal Opportunity Institution authorized to provide research, educational information and other services

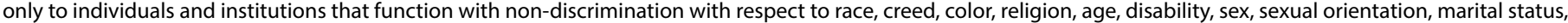

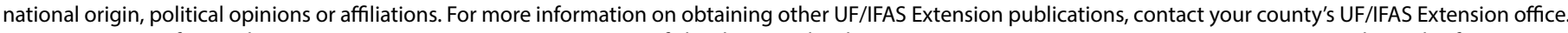
U.S. Department of Agriculture, UF/IFAS Extension Service, University of Florida, IFAS, Florida A \& M University Cooperative Extension Program, and Boards of County Commissioners Cooperating. Nick T. Place, dean for UF/IFAS Extension. 
temporarily due to a smaller leaf area available for photosynthesis. The rate of photosynthesis increases in the older remaining leaves for up to 40 days after pruning, which favors growth and development in the lower portions of the canopy.

Research indicates the total shoot length is significantly reduced for the subsequent year when pruned during the summer. The main factor seems to be the length of time the regenerated shoots can grow before dormancy is induced; this must be considered if pruning is included in a summer management plan. There is an inherent root-to-shoot growth balance that the tree is constantly trying to maintain. An unpruned tree grows fewer shoots to keep up with the expanding root system than a tree that has been pruned more heavily.

One of the goals of summer pruning is to bring the canopy size under control by encouraging a larger number of lateral branches growing along a greater span of the main scaffolds, effectively keeping the root-to-shoot balance intact on a smaller framework (Figure 2). This smaller framework favors efficient crop production because harvestable fruit is within arm's reach, thinning can be done from the ground, and spray treatments can have better coverage. Keeping the canopy size more compact will also reduce the need for ladders and allow harvesting from ground level, which improves picking efficiency. The amount of pruning required in winter is greatly reduced and pruning cuts in winter take longer to heal than cuts made on actively growing shoots in the summer. This lowers the overall incidence of disease infiltrating pruning cuts.

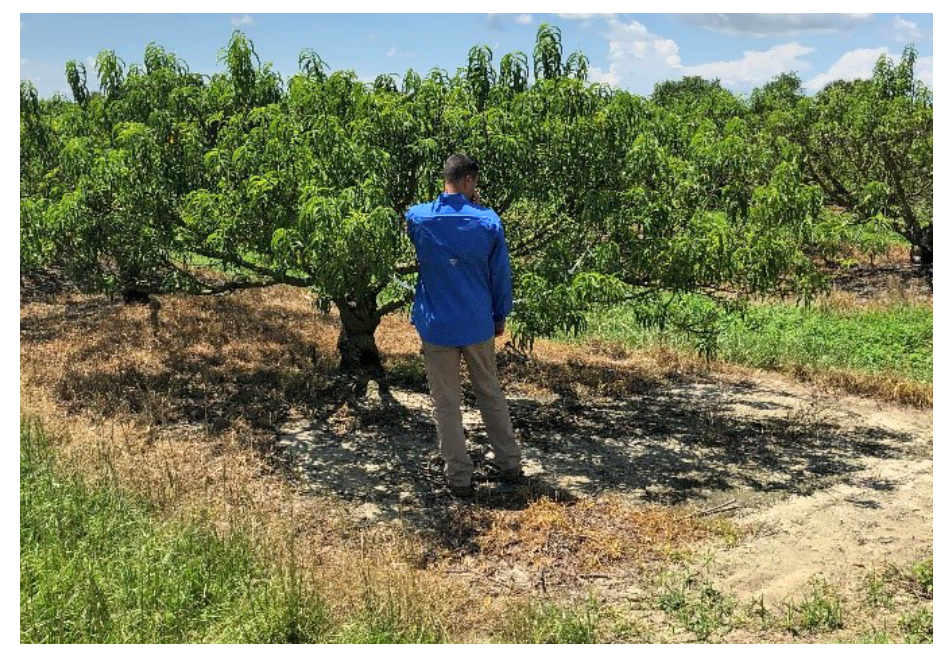

Figure 2. Ten-year-old peach tree 'UFSun' grown in Fort Pierce, Florida. Credits: A. Sarkhosh, UF/IFAS

Winter pruning alone is insufficient to prevent the center of the trees from becoming overly shaded during summer in many cases. Meanwhile, summer pruning can ensure that the center of the tree is receiving the adequate light distribution needed for appropriate growth and development, which will allow more fruiting wood to develop lower in the tree. Tree centers usually become less productive year by year due to increased shading. Summer pruning has been found to shift the production of reproductive wood from mostly the upper portion of the canopy into the lower and intermediate portions of the canopy, including wood that emerges directly from the scaffolds. Thus, peach trees pruned in the summer restore their root/shoot balance with this growth and remain smaller than trees only pruned in the winter, which have a majority of new growth in the upper portion of the canopy. This redistribution of growth means that the trees prioritize branch regrowth over radial trunk expansion, resulting in reduced tree size and vigor.

Foliar diseases are more common during the summer when vegetative growth gets dense and causes increased humidity and decreased airflow. Peach rust (Tranzchelia discolor) is considered an important postharvest fungal foliar disease in the Florida climate, where summer rainfall provides favorable conditions for peach rust development (Figure 3 ). If not managed, this disease causes early defoliation with a significant negative impact on next season's flowers and fruit (https://edis.ifas.ufl.edu/hs1263). All currently available peach cultivars in Florida are susceptible to the disease. Increased airflow associated with pruning will help reduce disease pressure. Altering the canopy structure this way can also improve the penetration of foliar sprays used to address disease or pest issues.

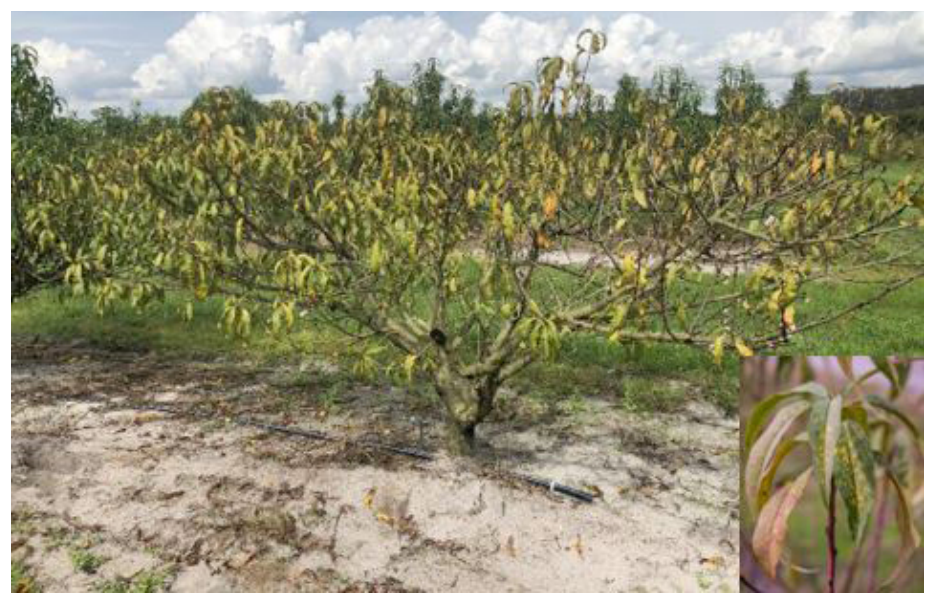

Figure 3. Peach tree 'UFSun' infected with peach rust. Credits: A. Sarkhosh, UF/IFAS

Differentiation of buds has also been found to be improved by summer pruning, leading to more uniform shoot sprouting and higher-quality flower buds. Summer pruning also strengthens scaffold branching, which means heavier crop loads can be tolerated, and breakage and/or splitting during freeze protection events is minimized. Increasing the strength of scaffolds will be important because of heavy 
crop loads caused by an increased number of flower buds and more concentrated fruit maturation associated with summer pruning.

\section{When and How to Summer Prune}

Choosing the best time to summer prune will depend on several factors. In Florida, the first summer pruning can begin 12 to 18 months after planting, depending on the time of year trees are planted. Do not prune if trees have less than 18 inches of new growth, because the tree could be damaged. Allow the trees 4 to 5 months after making pruning cuts to have adequate renewal of shoots along with proper flower bud formation on those shoots. This is less of an issue in central and southern Florida, where there may be more time to begin the pruning after harvest and before the trees go into dormancy or are purposely defoliated. In Florida, for mature peach trees, begin summer pruning soon after harvest has finished (May) and continue until two to three weeks after harvest.

Summer pruning is performed to favor branch induction of shoots through pinching or cutting the upper parts, sometimes multiple times in a year. The first manual (first-year) topping is implemented when the shoots exceed 40 inches $(100 \mathrm{~cm})$ from the soil. The second manual topping is done when the shoots exceed 60 inches $(150 \mathrm{~cm})$ from the soil (Figure 4). Mechanical topping is generally applied when the shoots exceed 7 feet $(200 \mathrm{~cm})$ from the soil, and manual pruning is done to thin the main branches down to four to five in number (Figure 5). However, it is highly recommended to leave some weak lateral growth in the inside of the canopy to protect limbs from sunburn.

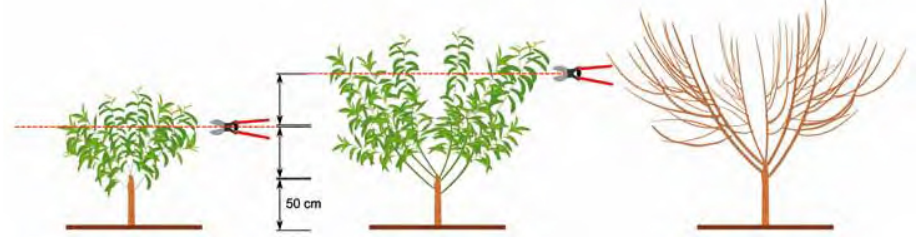

Figure 4. First manual topping is applied at about 40 inches $(100 \mathrm{~cm})$ above the soil. Center: Second manual topping is applied about 60 inches $(150 \mathrm{~cm})$ above the soil. Right: tree shape at the end of the first year.

Credits: D. Neri and F. Massetani, Università Politecnica delle Marche, Italy (Neri, D., and F. Massetani 2011)

The ultimate aim of summer pruning is to allow light to penetrate inside the canopy. This will help the tree to develop good flower buds and will induce the growth of new fruiting wood close to scaffold branches for the next season. At summer pruning:

- Remove suckers.
- Cut out strong growth/strong water shoots in the tree center and leave weak lateral growth to protect limbs from sunburn.

- Perform manual or mechanical topping ( $\sim 7$ to 8 feet).

- Eliminate some laterals if the growth is excessive.

- Do not allow old fruiting wood in the body of the tree to develop into heavy branches.

- Remove old fruit and dead shoots.

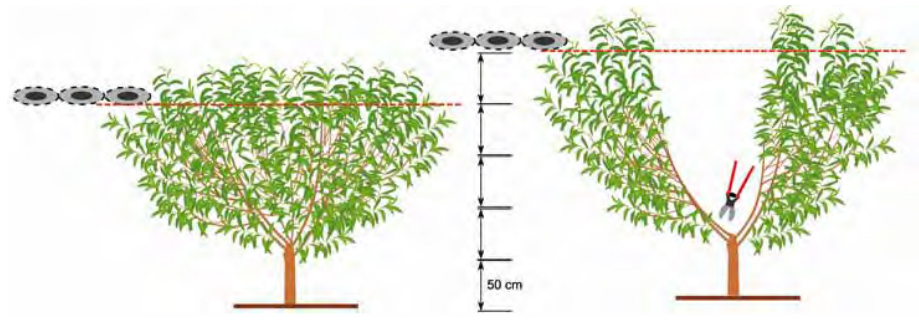

Figure 5. Open-center or vase training system during the second growing season. Left: The first mechanical hedging is applied at about 7 feet $(200 \mathrm{~cm})$ above the soil. Right: After mechanical pruning, hand pruning is used to thin the main branches down to four to five in number. It is highly recommended to leave some weak lateral growth in the inside the canopy to protect limbs from sunburn.

Credits: D. Neri and F. Massetani, Università Politecnica delle Marche, Italy (Neri, D., and F. Massetani 2011)

\section{How to Summer Prune a Mature Peach Tree Step-by-Step}

By the time harvest has finished and summer is in full force, peach trees older than a few seasons are likely very dense with new growth and a little out of control, as seen in the 3-year-old tree in Figure 6. Remember that it is best to use clean and sharp tools for pruning, because this helps to prevent the spread of disease. Loppers are the tool used most often, but hand pruners and hand saws will handle smaller and larger branches, respectively, if needed. After pruning, a fungicide spray application is suggested, if not already part of the summer spray schedule.

Step 1: Cut the back tree to a manageable height of 6-8 feet. The sides can also be trimmed back 1-2 feet to maintain the alleyway width convenient to move equipment through the orchard. This step can be done either by hand pruning, disc pruning, or cutter bars attached to machine hedgers (Figure $6)$.

Step 2: Starting from the ground up, remove suckers coming from the rootstock. These can compete with the scion for water, nutrients, and light. Figure 7 also illustrates the need for weed control in summer. 


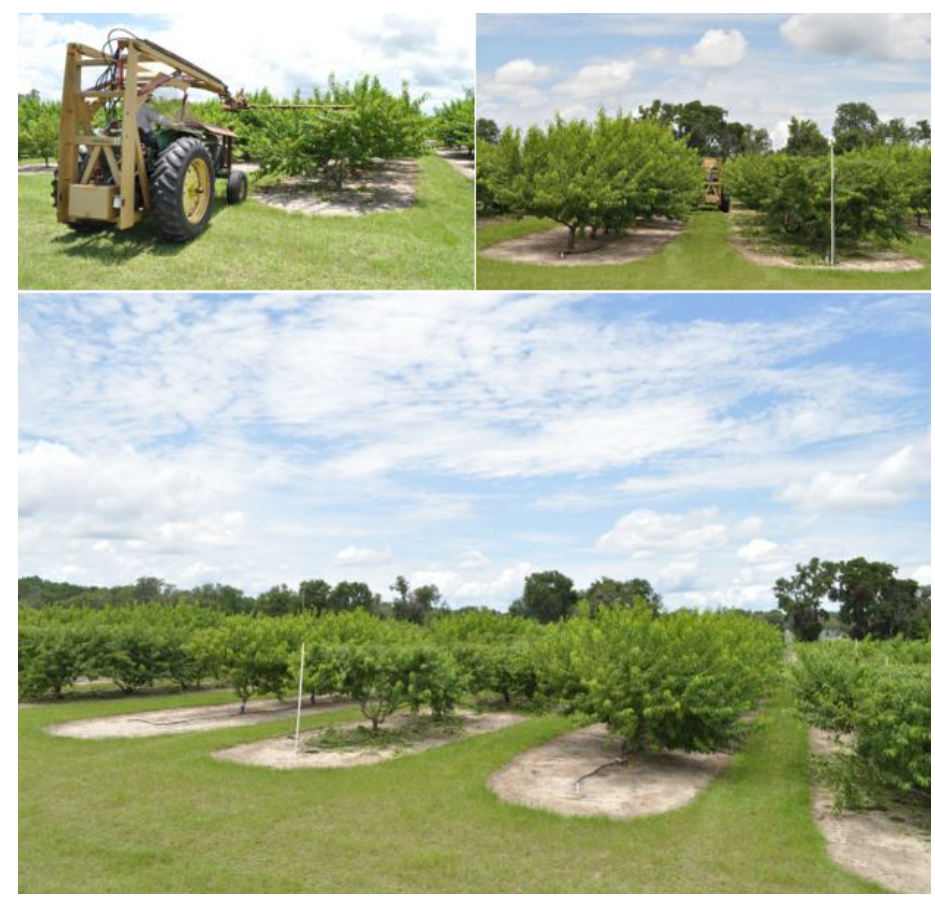

Figure 6. Top back the tree to a manageable height. Credits: D. Huff, UF/IFAS

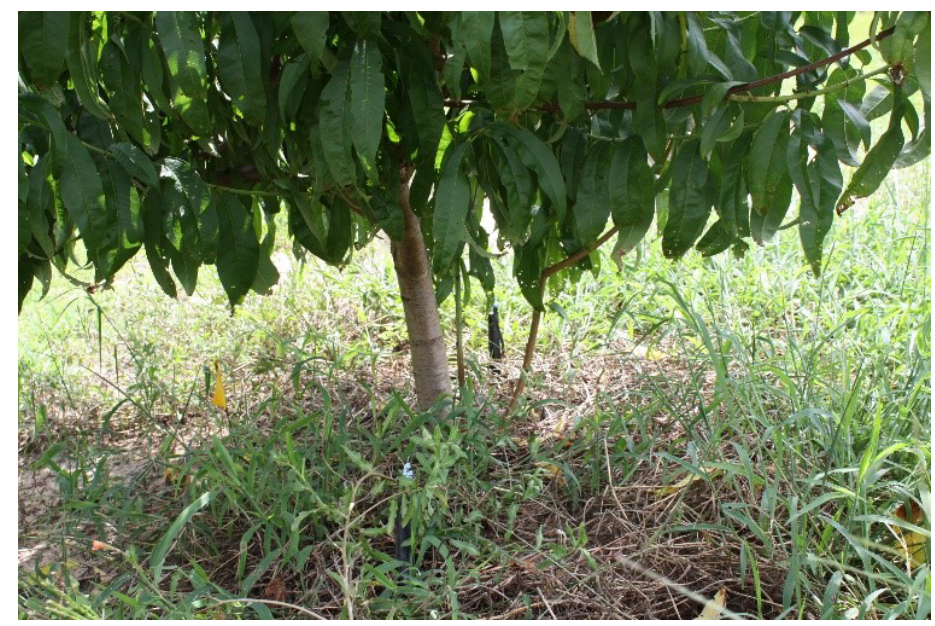

Figure 7. Remove all growth, including suckers, within two feet of the ground.

Credits: J. Popenoe, UF/IFAS

Step 3: Remove overly vigorous branches that are growing upright higher up where the main lateral branches split from the trunk in the center of the canopy. These branches are referred to as water shoots, which continue growing for much of the season when other lateral branches have slowed growth. Also, remove branches that are rubbing or crossing into the middle (Figure 8). Some smaller lateral branches should be left or cut in half to provide shade to the trunk to help prevent bark cracking by sunburn.

Step 4: Head back (manually or mechanically) branches with excessive blind nodes, which are sections of branches with no growing buds or leaves (Figure 9). Remove some laterals if growth is excessive. Remove any dead branches as well.

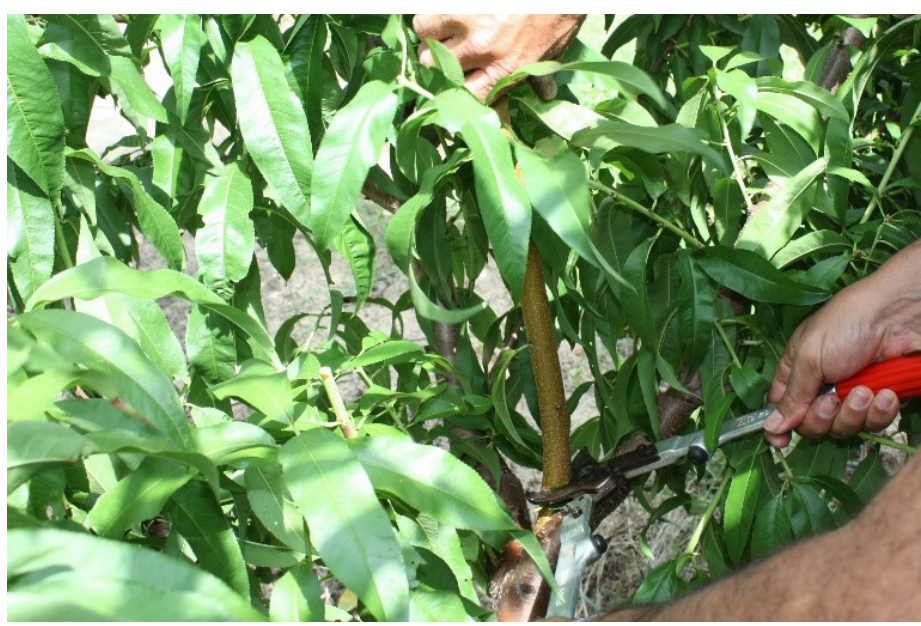

Figure 8. Remove strong water shoots in the center, while leaving weak lateral growth to protect scaffold sunburn. Credits: J. Popenoe, UF/IFAS

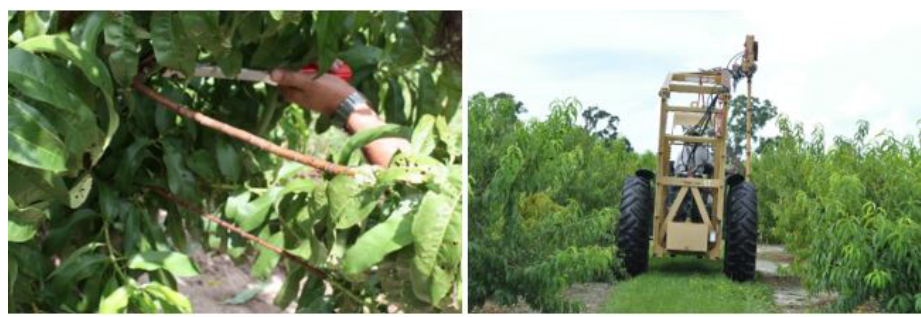

Figure 9. Prune back branches with excessive blind nodes to the growth point.

Credits: J. Popenoe, UF/IFAS

Step 5: To keep the height lower, head back the main terminal shoots on many branches to remove apical dominance, usually to a lateral (Figure 10). Reduce the lateral branches by $1 / 3$ as well if they are long.

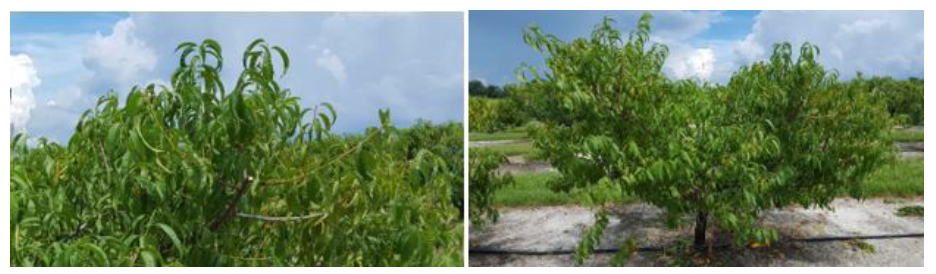

Figure 10. Manual lateral thinning.

Credits: J. Popenoe and D. Huff, UF/IFAS

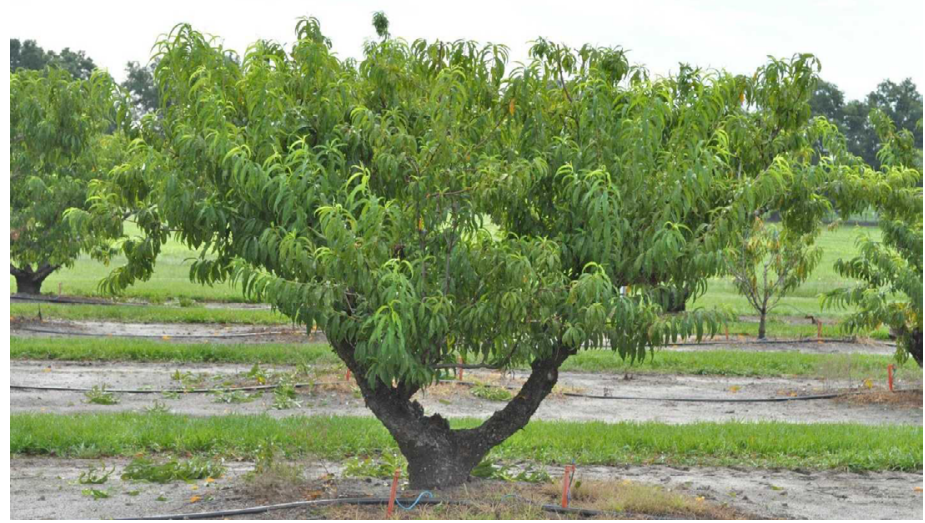

Figure 11. A finished example of summer-pruned peach tree 'Tropicbeauty' grown in Citra.

Credits: D. Huff, UF/IFAS 


\section{References}

Ferree, D. C., S. C. Myers, C. R. Rom, and B. H. Taylor. 1984. "Physiological Aspects of Summer Pruning." Acta Hort. 146:243-252.

Fruit Growers News. 2019. "Correct Summer Pruning for Peach Trees Stressed.” Viewed March 12, 2020. https:// fruitgrowersnews.com/news/correct-summer-pruningtechniques-for-peach-trees-stressed/

Hanlin, B., and J. Gryder. 2015. "Can You Prune Peach Trees in Summer? Yes!” North Carolina Cooperative Extension. Viewed March 12, 2020. https://wilkes.ces.ncsu. edu/2015/07/can-you-prune-peach-trees-in-summer-yes/

Neri, D., and F. Massetani. 2011. "Spring and Summer Pruning in Apricot and Peach Orchards." Adv. Hort. Sci. 25 (3): 170-178.

Sharif Hossain, A. B. M., F. Mizutani, M. O. Justus, A. R. ElShereif, and K. L. Rutto. 2006. "Effect of Summer Pruning on Shoot Growth and Fruit Quality in Peach Trees Trained as Slender Spindle Bush Type." Mem. Fac. Agr., Ehime Univ. 51:9-13.

Strauss, E. 2014. "Fruit Trees: Summer Pruning vs. Winter Pruning." Northwest Edible Life. Viewed March 12, 2020. https://nwedible.com/

fruit-trees-summer-pruning-vs-winter-pruning/

University of California Division of Agriculture and Natural Resources. 2020. "Pruning and Training." Viewed March 12, 2020. http://homeorchard.ucanr.edu/The_Big_Picture/ Pruning_\&_Training/

Weber, M. E., R. A. Pilatti, M. H. Sordo, M. S. Garcia, D. Castro, and N. F. Gariglio. 2011. "Changes in the Vegetative Growth of the Low-Chill Peach Tree in Response to Reproductive Shoot Pruning after Harvesting." New Zealand Journal of Crop and Horticultural Science 39 (3): 153-160. 